\title{
DESENVOLVIMENTO RURAL E CONSERVAÇÃO DO CAMPO
}

Francisco Cordovil

Dezembro 1997

WP $\mathrm{n} \cong 1997 / 07$

DOCUMENTO DE TRABALHO

WORKI NG PAPER 


\section{Desenvolvimento Rural e Conservação do Campo}

Francisco Cordovill

WP $97 / 07$

Dezembro de 1997

\section{Í NDICE}

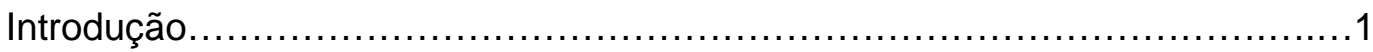

I. Um contexto de profunda mudança.............................................

II. Desenvolvimento rural: novas realidades, outro caminhos..................... 4

II.1. Regiões rurais - os desafios actuais................................

II.2. Desenvolvimento rural - objectivos e princípios orientadores..........6

III. Desenvolvimento Rural e Conservação: desafios e perspectivas...............7

III.1. Demarcando novas fronteiras de análise............................8

III.2. O campo - processos e actores da sua valorização e conservação..9

III.3. Perspectivas e dúvidas maiores....................................12 


\section{NTRODUÇÃO}

Tendo como pano de fundo a trajectória histórica e a situação actual da sociedade portuguesa, no contexto mundial, e a recente evolução das políticas agrícolas e de desenvolvimento regional no quadro da União Europeia (UE), discute-se neste documento a relação entre os processos de desenvolvimento rural e a conservação dos recursos naturais, privilegiando-se a temática das perspectivas de valorização ambiental das regiões rurais onde dominam sistemas de produção agroflorestais de carácter extensivo.

Palavras Chave:

Desenvolvimento rural; conservação e valorização do campo; bens públicos; estratégias territoriais.

\section{UM CONTEXTO DE PROFUNDA MUDANÇA}

Portugal é um pequeno país muito aberto ao exterior, profundamente marcado pelo recente processo de integração na União Europeia. Numa posição periférica e atrasada neste contexto geoeconómico, o país e em particular a sua agricultura e regiões rurais vêm enfrentando desde a adesão plena à CE, em 1986, um processo de exigentes ajustamentos, só parcialmente compensados pelas ajudas financeiras recebidas. Tal processo de ajustamento foi ditado pela dupla exigência da harmonização à disciplina comunitária e do acompanhamento dos novos passos que a Comunidade empreendeu em matéria de integração (Mercado Único, UEM), de alargamentos e de relacionamento externo, no quadro de uma situação geopolítica europeia profundamente alterada pelo desmoronar da URSS e pela reunificação alemã.

A compreensão desta conjuntura histórica e da especificidade geoestratégica portuguesa deve ser iluminada por um duplo esforço de alargamento do nosso olhar, para podermos apreender as tendência pesadas que vêm moldando a nossa vida social e as linhas de força fundamentais que presidem à reconfiguração que o mundo está a sofrer.

Trata-se em particular de observar que vivemos num mundo em transe, cada vez mais 'pequeno', onde a emergência de novas oportunidades se associa à multiplicação de novos e intensos fenómenos de exclusão e tensão cultural, social e territorial. Um mundo em transe porque afectado por um ritmo vertiginoso de mudança, que ultrapassa os tempos de resposta humana ao nível da compreensão e, por maioria de razão, ao nível das soluções institucionais. Um mundo mais'pequeno' porque pela primeira vez na história humana um sistema social - o capitalismo - se apresenta em condições de poder ditar as suas leis à escala mundial, num quadro onde as barreiras nacionais enfraquecem e as pessoas e territórios se tornam cada vez mais 'próximos'. Um mundo de novas exclusões e conflitos porque o capitalismo, ao mesmo tempo que reafirma a sua enorme vitalidade e adaptabilidade histórica, revela também a sua inelutável propensão para despoletar novas contradições entre as necessidades de acumulação (seu fundamento primeiro) e 
as aspirações e necessidades humanas, estejam estas ancoradas em conquistas 'históricas' anteriores ou em novas atitudes civilizacionais.

Um esboço das profundas e sucessivas mudanças que a sociedade portuguesa sofreu nos último quarenta anos, e dos correspondentes impactes territoriais, poderá estruturar-se em torno dos seguintes processos: significativo crescimento económico, acompanhado de industrialização e de forte aumento das transacções económicas com o exterior; intensos êxodos agrícola e rural, associados à explosão da emigração e ao grande crescimento das áreas metropolitanas; alteração dos níveis e dos modelos de consumo; envelhecimento demográfico; transição de um regime ditatorial para uma democracia representativa; descolonização; retorno e imigração; forte densificação de redes e meios de comunicação e de circulação de pessoas e bens; elevação das aspirações sociais e culturais e maior democratização da escola, sobretudo aos níveis secundário e superior; extensão e mudança da intervenção administrativa e reguladora do Estado; integração europeia num quadro de mundialização económica. Se reflectirmos sobre esta trama tão densa e diversificada de processos de mudança que atravessaram a sociedade portuguesa no curto período de uma geração, poderemos perceber:

- Que eles revelam algumas linhas de força persistentes, como sejam: a abertura ao exterior e a integração europeia; o crescimento económico conjugado com industrialização, terciarização e urbanização; a maior democratização e integração cultural; e a redução das barreiras à mobilidade e comunicação inter-territorial.

- Que os mesmos processos se traduziram num profundo impacte na distribuição espacial da população e das actividades económicas, implicando nomeadamente um substancial reforço dos meios urbanos face aos meios rurais e uma alteração radical das relações entre eles.

- Que a duração muito curta deste ciclo histórico conduz a que uma grande parte da população adulta portuguesa, ao ter acompanhado tais transformações, guarde na sua memória e reflicta na sua mentalidade e práticas actuais os sucessivos 'tempos' e 'espaços' que lhe foi dado viver, o que se traduz em particular no facto de muitos de nós combinarmos uma vivência tipicamente urbana, com uma memória e laços vivos de carácter rural (apego aos sítios, vínculos pessoais, hábitos e gostos, visão dos problemas, etc). Este é um dos traços que permite caracterizar a actual fase como de transição, ajudando-nos a perceber a clivagem de atitudes entre as diferentes gerações a este propósito e estimulando-nos a descobrir novos caminhos de relação e solidariedade entre territórios urbanos e territórios rurais.

Aproximando-nos um pouco mais do núcleo da presente comunicação, importa caracterizar as tendências principais que vêm moldando as políticas agrícolas e de desenvolvimento rural nos países desenvolvidos de economia de mercado. À relativa estabilidade das concepções e políticas de desenvolvimento regional que caracterizou o período desde o pós-guerra às crises dos anos setenta, vieram a suceder-se várias gerações de novas políticas, caracterizadas nomeadamente pela alteração dos lugares e papéis atribuídos à agricultura e aos espaços rurais. Na visão tradicional, que acompanhou as três décadas de crescimento 'virtuoso' do pós-guerra, o desenvolvimento da agricultura e dos espaços rurais era encarado como processo de modernização obtido por difusão dos impulsos tecnológicos e de mercado gerados pelo crescimento industrial e pela expansão urbana, uns e outros territorialmente polarizados. 
No contexto de crise que marcou os anos setenta, a agricultura e o espaço rural vieram a ser invocados como factores de amortecimento dos impactes económicos e sociais de tal crise e revalorizados como fontes de recursos e iniciativa endógenos.

Mais recentemente, assistiu-se a uma reconceptualização e alteração de políticas de desenvolvimento regional, marcada pela tentativa de conciliar os princípios de eficiência económica e da coesão social.

Em estreita conexão com este movimento, o estatuto da ruralidade e o lugar e funções da agricultura, bem como as políticas correspondentes, tendem a ser drasticamente reconsiderados, num quadro em que as decisões de carácter supra-nacional assumem cada vez maior precedência e prevalência sobre as de carácter nacional. É sobre esta última fase que iremos concentrar a nossa atenção, abordando-a na perspectiva particular da UE.

A interligação entre o encerramento das negociações do Uruguay Round, que conduziu à maior liberalização e abertura das relações económicas internacionais através de uma revisão dos acordos do GATT, e a Reforma da PAC, em 1992, evidenciou as dificuldades de a UE vir a manter políticas agrícolas fortemente proteccionistas no domínio agrícola, num contexto de globalização onde se perfilam fortes interesses exportadores nesse domínio encabeçados pela potência dominante no plano mundial (EUA). Mas as pressões no sentido da reorientação profunda da PAC entroncaram também noutros factores de que se destacam, por um lado, a perversidade da anterior situação em matéria de custos orçamentais e de iniquidade social e territorial intracomunitária e, por outro, os desafios resultantes dos novos alargamentos e aprofundamento da UE.

A Reforma de 1992 corrigiu parcialmente o proteccionismo de mercado da PAC e diversificou as suas frentes de intervenção (medidas agroambientais, florestais e reformas antecipadas). No entanto, manteve as ajudas directas ao rendimento dos agricultores indexadas anualmente às áreas de cultura (ponderadas por produtividades históricas) e aos efectivos pecuários, continuando assim a concentrar os apoios financeiros nos segmentos produtivos e regiões mais competitivas da agricultura comunitária e desencorajando as mudanças tecnológicas e de especialização produtiva no sentido de uma maior eficiência. Além disso, a reforma das OCM dos produtos mais característicos das agriculturas do sul (frutas e legumes; vinho) foi diferida para mais tarde e tem sido tratada de modo menos favorável para os produtores que as OCM 'tradicionais', contrariando expressamente expectativas anteriormente criadas por declarações formais do Conselho.

Num balanço global poderá, pois, dizer-se que a Reforma de 1992 abriu perspectivas promissoras de maior eficiência e equidade, em particular pela valorização de novos objectivos e domínios de intervenção (reconhecimento da multifuncionalidade da agricultura ao serviço do desenvolvimento rural), mas manteve-se ainda demasiado vinculada aos interesses de partida, não incentivando suficientemente a mudança e tornando muito mais pesados os mecanismos de gestão e de controlo administrativo. 
Entretanto acumulam-se os indícios de que a PAC deverá vir a ser novamente modificada em articulação com uma reforma global das políticas estruturais da UE. Com alguma margem de incerteza, antecipam-se os contornos prováveis destas novas reformas, que poderão começar a tomar corpo na sequência da Conferência Inter-Governamental a realizar a partir da primavera de 1996: maior articulação dos Fundos Estruturais; políticas de coesão mais selectivas territorialmente, mais focadas na promoção dos objectivos emprego e qualidade ambiental, mais exigentes na fundamentação das estratégias de desenvolvimento regional e local e menos abertas a uma protecção indirecta de interesses adquiridos de base sectorial, nomeadamente agrícola; criação de mecanismos financeiros que permitam moderar os efeitos de choques conjunturais territorialmente concentrados e resultantes do cumprimento das políticas de convergência nominal; continuação do movimento de aproximação dos preços agrícolas comunitários aos preços mundiais; manutenção de ajudas directas ao rendimento dos agricultores, mas desconectando-as da indexação a àreas de cultura ou a efectivos pecuários específicos, de modo a favorecer especializações agroflorestais mais eficientes.

O cenário delineado no parágrafo antecedente seria positivo, nomeadamente para países como Portugal. Não sendo improvável, é possível que não venha a concretizar-se em toda a sua extensão: primeiro, porque a estratégia actual de caminho para a UEM poderá fracassar ou vir a marginalizar os países do sul; segundo, porque existe o perigo de prevalecer a tendência de renacionalização das políticas socioestruturais, centrando-se os esforços comunitários na gestão das políticas macroeconómicas cambial e monetária e na coordenação das políticas orçamentais; terceiro, porque os 'lobbies' sectoriais e regionais mais poderosos ancorados na PAC actual poderão, mais uma vez, travar a sua racionalização e a adopção de políticas de desenvolvimento rural mais ajustadas.

\section{DESENVOLVI MENTO RURAL: NOVAS REALI DADES, OUTROS CAMI NHOS}

Em virtude das transformações anteriormente assinaladas, Portugal_apresenta hoje um quadro de distribuição territorial da população com o seguinte tipo de perfil ${ }^{4}$.

${ }^{1}$ Esboço com base no Estudo de Avaliação dos Programas Regionais em Portugal, GEOIDEIA, 1993. A estatística em que se apoiam os cálculos referentes à população é o Censo de 1991. 


\begin{tabular}{|l|l|l|l|l|l|}
\hline & $\begin{array}{l}\text { População } \\
\text { № }\end{array}$ & $\begin{array}{l}\text { Área } \\
\text { Km2 }\end{array}$ & $\begin{array}{l}\text { Densidade } \\
\text { Hab/Km2 }\end{array}$ & $\begin{array}{l}\text { População } \\
\text { \% do } \\
\text { Continente }\end{array}$ & $\begin{array}{l}\text { Área } \\
\text { Continente }\end{array}$ \\
\hline A. Metropolitanas & $\begin{array}{l}364039 \\
5\end{array}$ & 3435 & $\mathbf{1 0 6 0}$ & $\mathbf{3 8 , 8}$ & $\mathbf{3 , 9}$ \\
\hline Intermédias & $\begin{array}{l}353279 \\
2\end{array}$ & 24363 & $\mathbf{1 4 5}$ & $\mathbf{3 7 , 7}$ & $\mathbf{2 7 , 5}$ \\
\hline Rurais & $\begin{array}{l}219826 \\
1\end{array}$ & 60882 & $\mathbf{3 6}$ & $\mathbf{2 3 , 5}$ & $\mathbf{6 8 , 6}$ \\
\hline Continente & $\begin{array}{l}937144 \\
8\end{array}$ & 88680 & $\mathbf{1 0 6}$ & $\mathbf{1 0 0 , 0}$ & $\mathbf{1 0 0 , 0}$ \\
\hline
\end{tabular}

- Regiões de forte concentração urbana (metropolitanas), com elevado peso na população e escassa expressão em termos territoriais. Regiões escassamente povoadas, largamente maioritárias em termos de área territorial mas minoritárias em termos populacionais. Inclui-se aqui a quase totalidade do Alentejo e do Norte e Centro Interiores, as zonas de montanha do Noroeste e ainda uma parte restrita do Centro Litoral.

- Áreas com grau intermédio de urbanização, diversificadas nos seus modelos territoriais e socioprodutivos e nas condições de inserção externa, com expressão significativa em termos de área e de população.

Este tipo de povoamento, caracterizado pela distribuição muito desigual da população no território, não constitui por si só um problema, sendo até típico de sociedades desenvolvidas. Do mesmo modo, não se considera necessariamente negativa a coexistência de modelos territoriais e socioprodutivos muito contrastados regionalmente; tal diversidade além de ser incontornável por razões de natureza histórica ou geográfica, pode até constituir-se em factor favorável ao desenvolvimento. Os problemas poderão estar sim nas desigualdades de oportunidades e de acesso a recursos essenciais à afirmação pessoal e ao desenvolvimento, que surgem frequentemente associados a tais contrastes territoriais.

\section{I.1. Regiões rurais - os desafios actuais}

Centrando a nossa atenção a partir daqui na problemática das regiões rurais (escassamente povoadas), e uma vez esboçada a sua importância em termos populacionais e espaciais e definidas as linhas de profunda mudança que as vêm moldando, interessa caracterizar os traços dominantes da sua realidade actual, de modo a enquadrar as perspectivas de desenvolvimento que se expõem a concluir este ponto.

Primeiro, as regiões rurais integram regra geral redes urbanas intermédias (médias/pequenas cidades e grandes/pequenas vilas) onde reside uma parte maioritária e tendencialmente crescente da população e que constituem o seu 'sistema nervoso central' (regulação intra-regional e comunicação/relação supra-regional). 
Segundo, as actividades terciárias lideram a estruturas do emprego regional; a agricultura continua a ser um dos eixos estruturantes da vida económica e social e um factor chave da conservação/qualificação ambiental, mas já não é, salvo raras excepções, a fonte principal de sustentação directa do emprego e do rendimento da população residente nas regiões rurais.

Terceiro, é muito forte a convergência de necessidades, de aspirações e de atitudes das pessoas residentes nas áreas rurais com as que residem nas áreas urbanas; esta convergência deve-se à integração cultural produzida nomeadamente pela escola e pelos meios de comunicação de massa, mas também à intensa mobilidade espacial das próprias pessoas, que tendem a repartir as suas vidas por territórios urbanos e por territórios rurais, através de modalidades crescentemente diversificadas (movimentos pendulares casa/trabalho; dupla residência; emigração sazonal; turismo; etc).

Quarto, a capacidade da procura endógena das regiões rurais para absorver os bens e serviços aí produzidos mantém-se em níveis modestos, dadas as limitações resultantes da sua escala populacional e a muito maior exposição dessa procura à concorrência externa (nacional ou estrangeira); estes efeitos são moderadamente contrariados pela expansão e diversificação do poder de compra dos residentes, mas de modo muito assimétrico no interior das próprias regiões, regra geral com ganhos relativos, por vezes substanciais, dos centros que lideram as suas redes urbanas.

Quinto, a dimensão mais crítica dos problemas das regiões rurais prende-se com a dificuldade de aceder a recursos e oportunidades que constituem factores nucleares dos processos de desenvolvimento mas que tendem a concentrar-se nas grandes aglomerações urbanas; referimonos em particular aos recursos humanos mais qualificados, aos modernos serviços às empresas e às possibilidades mais diversificadas de mobilidade social e profissional.

Sexto, o espaço rural tende a ser revalorizado como ambiente genuíno e de qualidade, que importa conservar em benefício e para usufruto também das populações urbanas; mas aumenta também a consciência de que, nas actuais condições de concorrência e de tecnologia, os agricultores só poderão assegurar o seu papel de produtores de territórios rurais saudáveis se a sociedade os apoiar enquanto tais e não apenas enquanto produtores de bens mercantis agroflorestais.

\section{II .2. Desenvolvimento rural - objectivos e princípios orientadores}

Com o enquadramento anteriormente traçado, o desenvolvimento rural poderá definir-se como a melhoria das condições de vida das pessoas residentes nas áreas e regiões rurais, através de processos sociais que respeitem e articulem os seguintes princípios: eficiência económica, equidade social e territorial, qualidade patrimonial e ambiental, sustentabilidade (conservação; condições de competitividade dinâmica/duradoura), participação democrática e responsabilidade cívica. 
As opções que fundamentam este conceito devem ser clarificadas através do enunciado de alguns requisitos considerados essenciais para os processos de desenvolvimento rural:

- necessidade de estratégias abertas e muito selectivas das colectividades territoriais rurais, procurando criar vantagens competitivas duradouras, assentes nos princípios de diferenciação, flexibilidade e qualidade;

- a abertura ao relacionamento com outros territórios e com agentes exógenos é a via aconselhável para gerar procuras suficientes para a produção regional e cimentar uma cultura inovadora e qualificante; ela exclui atitudes localista e fechadas, as quais podem contribuir para perpetuar as situações de exclusão e de dependência em vez de as combaterem;

- a necessidade de selectividade decorre do carácter extremamente duro da concorrência interterritorial num contexto de globalização, o qual se traduz na impossibilidade das regiões rurais europeias se poderem bater em condições competitivas duradouras seja no conjunto de actividades que pressupõem economias de aglomeração fortes, seja naquelas que se alimentam de concorrência pelo preço assente num aviltamento dos custos unitários dos factores de produção ou na concessão sistemática de incentivos financeiros;

- recusa da dicotomia 'mundo rural'/'mundo urbano'; tal dicotomia é inadequada no plano da compreensão da realidade contemporânea dos países desenvolvidos, é contrária aos valores de solidariedade e interdependência entre os meios rurais e urbanos, que interessa estimular, e tem prejudicado a formulação e concretização das políticas de desenvolvimento regional e local, nomeadamente em regiões rurais;

- defesa de uma intervenção proactiva e reguladora do Estado nos processos de desenvolvimento regional, nomeadamente rural, estimulando a iniciativa privada de índole empresarial ou associativa e apostando na capacidade de concertação, aprendizagem e responsabilização das colectividades territoriais, mas sem se esquivar às responsabilidades específicas que lhe cabem na defesa do interesse público;

- a intervenção do governo nestes domínios pressupõe a capacidade de definir, em tempo oportuno, estratégias de desenvolvimento e de ordenamento territorial do conjunto do espaço nacional, compatíveis com o contexto supra-nacional de inserção do país e susceptíveis de gerar mobilização de interesses e iniciativas suficientemente poderosos para prevalecer sobre os seus adversários, nomeadamente sobre os agentes que actuam em escala global numa lógica de especulação fundiária ambientalmente agressiva.

\section{DESENVOLVI MENTO RURAL E CONSERVAÇÃO: DESAFI OS E PERSPECTIVAS}

Neste fase da argumentação já sobressaiu a ideia de que a conservação de um ambiente natural genuíno e de qualidade constitui uma das condições chave para o desenvolvimento rural. Mas esta questão está ainda situada num plano demasiado vago, não revelando suficientemente as grandes dificuldades a enfrentar para converter tal intenção numa estratégia praticável. Interessa, pois, concretizar e especificar melhor a reflexão encetada. 


\section{III.1. Demarcando novas fronteiras de análise}

Dada a grande diversidade de contextos empíricos em que estes problemas se colocam e reconhecida a complexidade dos mesmos, além de nos continuarmos a referenciar apenas às regiões rurais escassamente povoadas de Portugal ou de países com características semelhantes, centraremos um pouco mais o nosso objecto de análise estabelecendo algumas fronteiras adicionais.

Opta-se por focar a reflexão sobre a articulação entre desenvolvimento rural e a conservação do recurso campo, sem que isso implique menosprezo pela necessária conservação de outros recursos igualmente indispensáveis à sustentação e progresso destas áreas rurais, nomeadamente do património edificado, das identidades culturais e dos saberes/fazer tradicionais. Além disso, centra-se a análise nas áreas rurais que apresentam o seguinte conjunto de atributos:

- ausência de oportunidades e pressões típicas das zonas confinantes com áreas metropolitanas, mas existência de razoáveis condições de acessibilidade física; o clima é ameno, mas marcado por oscilações sazonais significativas; não se dispõe de recursos naturais ou outros que pela sua excepcional raridade gerem rendas de monopólio em termos turísticos; as potencialidades naturais disponíveis e previsíveis excluem a presença relevante de formas de agricultura competitivas num quadro aberto de concorrência baseada no factor custo e em produtos de massa; toda a paisagem rural reflecte os efeitos de uma presença humana continuada, encontrando-se os campos profundamente transformados por sucessões de usos e tecnologias de produção;

- as utilizações agroflorestais ambientalmente aconselháveis do território e nele presentes são de natureza extensiva, mas diversificada, combinando agricultura e criação de gado com sistemas silvo-pastoris e florestais; a capacidade de suporte directo de emprego no campo, baseado nestes sistemas, é muito fraca, não ultrapassando em regra um tempo completo de trabalho por cada cem hectares;

- todos os sistemas agroflorestais enfrentam ameaças de declínio, encontrando-se dependentes de ajudas públicas materializadas em intervenções directas no funcionamento dos mercados e em mecanismos complementares;

- a conservação do uso agroflorestal do campo, embora aberta a mudanças sensíveis de tecnologias e de estruturas produtivas, é considerada essencial quer para preservar recursos florísticos e faunísticos típicos das áreas em causa, quer para manter os espaço abertos à presença e frequência das pessoas residentes ou visitantes, quer finalmente para salvaguardar a tipicidade e beleza da paisagem.

As fronteiras de análise traçadas neste ponto poderão sugerir um estreitamento demasiado e perda de generalidade da reflexão. Essa legítima apreensão será moderada se nos apercebermos de que as realidades delineadas encontram expressão largamente maioritária em Portugal, como aliás em Espanha e noutras regiões do sul da Europa, e de que os comentários a este propósito são em boa medida generalizáveis a outros temas afins. 


\section{I.2. O campo - processos e actores da sua valorização e consenvação}

Sistematizam-se em seguida os elementos fundamentais do problema da conservação do campo enquanto factor de produção de bens económicos, no contexto empírico assinalado no ponto anterior'.

O campo serve de suporte a actividades humanas geradoras em simultâneo de bens e serviços mercantis, nomeadamente agroflorestais, e de bens e serviços de carácter público ou misto (paisagem, valores faunísticos e florísticos não comercializáveis, ambiente ameno e acessível).

O que confere carácter de bem público a alguns dos bens e serviços que o campo propicia não são as condições da sua produção e oferta (que no caso em apreço é essencialmente privada), mas sim as da natureza da procura: primeiro, porque eles podem ser usufruídos sem que seja possível proceder à sua divisibilidade e à exclusão individualizada dos utilizadores; segundo, porque o universo dos beneficiários além de incluir os utilizadores actuais (sobretudo residentes e visitantes, mas abarcando também os que acedem parcialmente a tais bens por via dos media) se alarga a todos aqueles que os poderão usufruir no futuro (valor de opção e de transmissão geracional) e até aos que prescindindo desse uso se sentem beneficiados pela preservação dos recursos em causa (valor de existência).

A conservação do campo, enquanto factor de qualidade ambiental, também só assume a relevância económica que lhe estamos a atribuir quando surge associada à percepção de que existe um problema de escassez, e portanto da necessária confrontação dos custos e beneficios de utilizações alternativas dos recursos que geram esses bens escassos. Nas circunstâncias em que a agricultura pode ser viável e eficiente apoiando-se apenas nos mecanismos de mercado e salvaguardando simultaneamente um ambiente de qualidade, sem necessidade de ajudas adicionais, os problemas que temos vindo a analisar perdem naturalmente grande parte da sua pertinência.

No caso vertente, à escassez juntam-se por vezes dois atributos adicionais que tornam as opções em causa mais críticas: a produção do campo e das amenidades associadas é muito lenta, mas a sua destruição pode ser rápida e irreversível.

Enquanto esta última circunstância sugere a urgência e a particular vigilância na conservação de tais recursos, uma outra actua justamente no sentido de dificultar a resposta atempada a tal desafio: a procura e valorização deste tipo de bens ambientais de carácter rural tende a crescer lentamente em paralelo com a elevação dos rendimentos médios da população urbana (elasticidade procura/rendimento positiva e forte) e com a saturação das pessoas face às tensões características da vida social nas zonas metropolitanas. Em síntese: embora a competitividade

\footnotetext{
${ }^{2}$ A agricultura apresenta-se muitas vezes como actividade fortemente agressiva do ambiente (água, solos, vegetação, fauna, etc.). Nessas circunstâncias as medidas de política devem subordinar-se a uma lógica preventiva e punitiva ("poluidor pagador"). No caso vertente a problemática empírica privilegiada é outra, centrando-se a análise económica na operacionalização do princípio do "beneficiário pagador".
} 
dinâmica das actividades baseadas nas amenidades rurais seja elevada, existe um perigo real de que isto venha a ser reconhecido demasiado tarde pelos seus produtores e beneficiários actuais e potenciais.

A estrutura complexa e difusa dos valores/beneficiários dos bens públicos gerados no campo torna muito difícil obter respostas operacionais às seguintes questões: como se fazem representar esses peneficiários? quanto e como estão dispostos a contribuir para usufruir dos bens em causa?

Dadas as dificuldades assinaladas no ponto anterior o Estado surge, regra geral, como actor nuclear quer na definição desse "quanto ?", quer na execução dos processos de repartição e intermediação financeira que concretizam o(s) "como(s) ?".

A mesma inorgacidade e heterogeneidade da procura dos bens públicos ambientais ajuda também a compreender porque razão as Organizações Não Governamentais (ONG) actuantes neste domínio constroem a sua legitimidade e força muito mais pela intensidade e qualidade de intervenção, e através da influência junto das instâncias de poder político estatal e dos media do que por actos formais constituintes de representatividade por delegação.

Nos parágrafos antecedentes o campo foi conceptualizado como factor de suporte de uma oferta diversificada de bens e serviços económicos, quer de natureza mercantil quer pública ou mista, à qual corresponde uma estrutura complexa da procura e da valorização social de tais bens.

Nos comentários seguintes destacar-se-ão algumas das condições e princípios a salvaguardar para que se concretizem estratégias territoriais favoráveis à conservação e valorização do campo.

Em primeiro lugar, considera-se não existir qualquer mecanismo regulador automático - o mercado ou outro - que garanta a convergência dos comportamentos económicos e sociais num sentido favorável à conservação do campo. Mas reputa-se também de insensata a ideia de tentar atingir este objectivo através do intervencionismo estatal. Assim, a via preconizada é a da concertação estratégica dos vários agentes/interesses em confronto, assente na clara demarcação e salvaguarda dos direitos e responsabilidades de cada interveniente e na identificação de objectivos comuns.

Neste entendimento, ao Estado competirá um papel nuclear quer como agente regulador e de dinamização estratégica do desenvolvimento rural, quer como intermediário político e financeiro na sustentação da oferta de bens públicos, nomeadamente ambientais, quer finalmente com agente disciplinador dos respectivos usos. A sua intervenção será igualmente decisiva na promoção de actividades de investigação e de divulgação técnica, que possam contribuir para uma compreensão mais fundamentada dos desafios e das soluções possíveis a adoptar nestes domínios. Evitará no entanto substituir-se à iniciativa privada, como proprietário ou gestor do património rural, salvo quando isso for imprescindível para salvaguardar a defesa do interesse público ou valores ambientais particularmente raros e sensíveis à intervenção humana; e nestes

\footnotetext{
${ }^{3} \mathrm{O}$ tema da valorização dos bens públicos ambientais, nomeadamente rurais, merece desde algumas décadas a atenção da comunidade científica, sobretudo na América do Norte, no Reino Unido e nos países escandinavos; mas o interesse pelo mesmo cresceu muitíssimo na última década, sendo a literatura recente disponível abundante, nomeadamente no domínio dos estudos empíricos. Os métodos mais utilizados neste âmbito, para tentar operacionalizar o princípio do "beneficiário pagador", baseiam-se: na inquirição aos beneficiários ("CVM - Contingent Valuation Method" ou "Survey Method"); na análise e ponderação dos custos de deslocação ("TCM - Travel Cost Method"); e na avaliação da influência da qualidade ambiental nos preços dos bens residenciais ("Property Value Method").
} 
casos excepcionais terá que enfrentar consequentemente as responsabilidades que toma para si, sem esquecer a cooperação inteligente e aberta, firme mas não dirigista ou policial, com os vários utilizadores dos territórios que administra. Finalmente compete-lhe garantir que os meios públicos transferidos para agentes privados são regular e competentemente gastos.

Aos produtores privados de território rural, com destaque para os agricultores e suas associações representativas, caberá a primordial responsabilidade na gestão do campo e portanto na garantia da conservação do respectivo valor ambiental, mas tal implicará a justa compensação pelos custos adicionais ou pelas reduções de proveitos resultantes da adopção de práticas geradoras de externalidades positivas ambientais, com eles contratualizadas, e que não se justificariam numa óptica estritamente privada. Além disso, deverão procurar promover, em conjunto com outros agentes das colectividades territoriais onde se inserem, o desenvolvimento de novas actividades económicas (turismo no espaço rural, serviços qualificados deslocalizáveis dos grandes centros, etc.) que possam internalizar os efeitos da qualidade ambiental, aliviando assim o esforço público na sua sustentação e contribuindo para o desenvolvimento económico e social das regiões onde operam.

Das ONG ambientalistas espera-se que actuem com imaginação e combatividade, de acordo com os seus objectivos específicos, mas nunca se esquecendo de que a primeira condição para conservar o campo é a manutenção do seu uso agrícola e ou florestal, sensato e esclarecido, mas também economicamente viável, e de que quanto maior for a capacidade da iniciativa privada para prover pelos seus próprios meios a sustentação ambiental, tanto maior será a margem de acção propiciada pelos fundos públicos, inexoravelmente escassos, afectáveis a essa finalidade. Cabe-Ihes pois uma acção de vigilância atenta e de pressão insistente sobre os outros actores, mas também a missão de ajudar a estabelecer e animar estratégias tecnicamente fundamentadas e socialmente viáveis de desenvolvimento territorial sustentável.

A concluir este ponto, gostaria de chamar a atenção para duas problemáticas territoriais portuguesas actuais, bem enquadradas nas fronteiras de análise definidas, que poderão servir de referência para testar o conjunto de perspectivas aqui propostas.

A primeira é de índole promissora: em pleno Baixo Alentejo Interior, encontra-se em fase inicial de concretização um plano zonal de natureza agroambiental, com apoio financeiro comunitário, visando conservar os sistemas agrícolas característicos da estepe cerealífera do Campo Branco, nomeadamente para salvaguardar os preciosos valores faunísticos (em particular, aves estepárias, com destaque para a Abetarda) que aquele habitat natural acolhe. Julgo que tal experiência cumpre no essencial o conjunto de princípios preconizados nesta comunicação.

Primeiro, pelo modo como um leque muito diversificado de actores se envolveram na preparação da estratégia adoptada; segundo pela consistência da sua fundamentação técnica; terceiro pela contratualização clara estabelecida entre os vários intervenientes.

Em contraste, numa zona que lhe é muito próxima, isto é na serra do Caldeirão que assinala a transição do Alentejo para o Algarve, surpreendemos uma paisagem imponente mas também 
angustiante: um mar imenso de cerros de xisto, topograficamente muito acidentado, apresenta-se revestido de montado de sobro e de azinho em estado de deplorável degradação e afundado em estevas. As árvores mortas, aos milhares, pontuam toda a paisagem como dedos acusadores para a insensatez da intervenção humana que consistiu na alargamento da cultura trigueira a todo este território, nos anos trinta e quarenta, e para a incapacidade ulterior e actual de recuperar ambientalmente este vasto espaço. O montado de sobro é reconhecido consensualmente como um dos recursos naturais mais importantes de Portugal e existe também uma consciência aguda da gravidade do seu actual estado sanitário em largas manchas territoriais; no entanto continua a não existir uma estratégia consequente de ataque a estes problemas. No âmbito das medidas florestais de acompanhamento da Reforma da PAC, Portugal beneficia actualmente de importantes apoios para constituição de novas arborizações de montado, que estão aliás a ser intensamente aproveitados, nomeadamente em virtude das generosas compensações financeiras que oferecem aos agricultores. Mas só intervenções territorialmente mais integradas, tecnicamente fundamentadas e politicamente determinadas poderão corrigir e recuperar situações com a gravidade e a dimensão da que aqui se regista.

\section{I .3. Perspectivas e dúvidas maiores}

Ser ambicioso e criativo, o homem encontrou na tecnologia o meio para gerir a sua insegurança e vontade de domínio perante a natureza. Igualmente inseguro nas relações com os seus semelhantes, procurou a previsibilidade e a garantia de protecção nas normas sociais, sobretudo nas de alcance mais duradouro e extenso, ou seja, nas que fundamentam as instituições.

De há uns dois séculos para cá, dada a ruptura aberta pela revolução industrial, o ritmo das transformações tecnológicas e os efeitos por elas libertados manifestaram-se avassaladoramente, testando até ao limite as possibilidades de resposta institucional da espécie humana. $O$ capitalismo, quando combinado com sistemas de democracia política, revelou uma notável capacidade de incorporação institucional das mudanças ditadas pelo progresso técnico e pelo crescimento económico; mas nem por isso se esbateram as ameaças e inquietações sobre a eventual emergência de desequilíbrios extremos na relação do homem com a natureza (destruição dos mecanismos básicos de regulação ambiental da bioesfera) e consigo próprio (exclusão social; terrorismo; guerra).

É à luz destas interrogações e desafios maiores, e não apenas de uma visão imediatista e tecnocrática, que questões como o futuro da UE e das suas políticas sectoriais e socioestruturais devem ser abordadas. 
Se pensarmos em termos da resposta simultânea aos desafios do alargamento e do relacionamento externo a Leste e a Sul, da defesa da competitividade e do emprego e do combate à exclusão social, facilmente concluiremos que o actual quadro institucional e de políticas da UE carece de adaptações bem mais globais e audaciosas do que as já desenhadas. Em particular, parece indispensável deslocar-se progressivamente o financiamento público às áreas rurais de uma lógica de protecção de rendas de situação adquiridas por certos segmentos dos produtores agrícolas, para uma outra onde prevaleçam objectivos de desenvolvimento rural territorial e socialmente equitativo e ancorado em necessidades e actividades duradouramente sustentáveis.

Neste contexto, a aposta na conservação do campo justificar-se-á não só em nome da garantia da biodiversidade e da qualidade ambiental, mas também da sustentação futura da competitividade e emprego dos produtores e dos territórios rurais.

O futuro, não muito distante, nos dirá se houve ou não no quadro europeu, nacional e ao nível das várias colectividades rurais, a visão e a capacidade suficientes para inflectir as políticas e as práticas de desenvolvimento rural num sentido mais justo e estimulante das sinergias entre a competitividade económica e a qualidade ambiental. 